\title{
Greater eosinophil counts at first COPD hospitalization are associated with more readmissions and fewer deaths
}

This article was published in the following Dove Medical Press journal: International Journal of COPD

\author{
Qing Li' \\ Pierre Larivée ${ }^{2,3}$ \\ Josiane Courteau ${ }^{2}$ \\ Simon Couillard ${ }^{2,3}$ \\ Thomas G Poder $2,4,5$ \\ Nathalie Carrier ${ }^{2}$ \\ Maryse Bélanger ${ }^{2,3}$ \\ Alain Vanasse $e^{2,5}$ \\ 'Center for Innovation Management \\ Research of Xinjiang, School of \\ Economics and Management, Xinjiang \\ University, Urumqi, Xinjiang, China; \\ ${ }^{2}$ Research Center, Centre Hospitalier \\ Universitaire de Sherbrooke \\ (CHUS), Sherbrooke, QC, Canada; \\ ${ }^{3}$ Respirology Service, Department \\ of Medicine, Faculty of Medicine \\ and Health Sciences, Université \\ de Sherbrooke, Sherbrooke, \\ QC, Canada; ${ }^{4} \mathrm{Health}$ Technology \\ Assessment Unit, UETMISSS, CIUSSS \\ de l'Estrie - CHUS, Sherbrooke, \\ QC, Canada; ${ }^{5}$ Department of Family \\ Medicine and Emergency Medicine, \\ Faculty of Medicine and Health \\ Sciences, Université de Sherbrooke, \\ Sherbrooke, QC, Canada
}

Purpose: The impacts of high blood eosinophil count (HBEC) at admission for COPD exacerbation on posthospitalization outcomes are still unclear. Previous studies have focused on its associations with first readmission rates; yet, its impacts on longitudinal outcomes such as subsequent readmissions still have to be explored. The main objective of this study is to investigate outcomes associated with HBEC following a first hospitalization for COPD exacerbation. Patients and methods: This is an observational cohort study design. We retrospectively analyzed data of patients with a first hospitalization within 5 years for COPD exacerbation between April 2006 and March 2013. Patients were stratified into the HBEC group if the blood eosinophil count at admission was $\geq 200$ cells $/ \mu \mathrm{L}$ and/or $\geq 2 \%$ of the total white blood cells. With information on exact dates of subsequent hospitalizations and death, we modeled readmissions and death as states in a multi-state Markov model and estimated transition probabilities to the next states. Sensitivity analyses were performed by varying thresholds for the definition of $\operatorname{HBEC}$ ( $\geq 300$ cells $/ \mu \mathrm{L}$ and/or $\geq 3 \%$ ).

Results: A total of 479 patients were included, of which 173 had HBEC. The transition probabilities for a first readmission was 74\% (95\% CI, 66\%-83\%) for patients with HBEC vs 70\% (95\% CI, 63\%-77\%) for patients with normal blood eosinophil count (NBEC). The transition probabilities for a second readmission were $91 \%$ (95\% CI, 84\%-100\%) for HBEC patients in contrast with $83 \%(95 \%$ CI, $74 \%-92 \%)$ for NBEC patients. Meanwhile, transition probability for death was lower in patients with HBEC. The differences enlarged in sensitivity analyses with higher cutoff.

Conclusion: Greater blood eosinophil cell counts during a first hospitalization for COPD predict increased susceptibility to up to two readmissions. These patients may however have a lower risk of death.

Keywords: COPD, blood eosinophil cell count, exacerbations, readmissions, death, multi-state Markov model, transition probability, observational cohort study, clinical data, administrative data

\section{Introduction}

COPD results in irreversible decline in lung function, ${ }^{1}$ affects 210 million people worldwide, and is the major cause of $5 \%$ of all deaths according to the WHO. ${ }^{2} \mathrm{COPD}$ accounts for the highest rates of hospitalization and highest number of readmissions in Canada among all chronic illnesses. ${ }^{3}$ The 30 -day readmission rates are as high as $20 \%$ in the $\mathrm{USA}^{4}$ and pay-for-performance programs have begun targeting COPD outcomes. ${ }^{5}$ In Canada, it was found that one hospitalization for acute exacerbation could cost up to $\$ 14,266 .{ }^{6}$ It has been estimated that COPD will become the third leading cause of death worldwide in $2030 .{ }^{7}$ One of the difficulties in managing COPD
Correspondence: Alain Vanasse Département de médecine familiale et de médecine d'urgence, 300I, I2th Avenue North, Sherbrooke, QC, Canada JIH $5 \mathrm{~N} 4$

Tel +I 8I9 82I 8000 ext 70540

$\mathrm{Fax}+\mathrm{I} 8195645386$

Email alain.vanasse@USherbrooke.ca
International Journal of COPD 2019:|4 33|-34|

(c) (i) ( 2019 Li et al. This work is published and licensed by Dove Medical Press Limited. The full terms of this license are available at https://www.dovepress.com/terms.php cc. hereby accept the Terms. Non-commercial uses of the work are permitted without any further permission from Dove Medical Press Limited, provided the work is properly attributed. For permission for commercial use of this work, please see paragraphs 4.2 and 5 of our Terms (https://www.dovepress.com/terms.php). 
is the heterogeneity of this complex disease in terms of its progression; ${ }^{8-10}$ this complexity is also evident in acute exacerbations of COPD. ${ }^{11}$

Given the high rates of hospitalization and high number of readmissions among all chronic illnesses, it is of primary importance to find a biomarker that could predict readmission outcomes and direct targeted treatment strategies. ${ }^{12}$ While classically neutrophilic, an important subset of COPD patients demonstrates eosinophilic inflammatory profile. ${ }^{13}$ Sputum eosinophilia is not available in many cases $;{ }^{14}$ meanwhile, studies have demonstrated that patients with high blood eosinophil levels behave similarly in comparison to those with high sputum eosinophil. ${ }^{15-20}$

The impact of blood eosinophil levels on readmission rates is an ongoing research question: some studies showed increased readmissions, ${ }^{21-23}$ others did not find significant effect; ${ }^{19}$ and another study found negative association between readmissions and eosinophilic exacerbations. ${ }^{24}$ Among these conflicting results, Couillard et $\mathrm{al}^{21}$ argued that a potential confounding factor might be the timing of corticosteroid administration, which could have masked peripheral eosinophilia. Excluding the patients who recently received systemic corticosteroids, they found a significant increase in 1-year COPD readmission associated with high blood eosinophil counts (HBECs). Using a bigger sample of patients, two follow-up studies found that eosinophilia at admission for a first severe exacerbation of COPD, when assessed in a time frame free of systemic corticosteroids, was associated with a significant increase in 1-year readmission for COPD and a shorter time to first COPD-related readmission; ${ }^{12}$ additionally, eosinophilic patients were associated with higher readmission costs. ${ }^{25}$

While long-term survival of COPD patients was studied occasionally, ${ }^{26}$ few studies have explored COPD-related readmissions apart from the first readmission. It is nonetheless meaningful to extend our focus beyond the yes/no question of the first readmission. Additionally, existing studies typically analyzed the outcomes one by one (hospital release, stay out of hospital, readmissions, death, etc), yet it would be of interest to avoid studying different outcomes separately because one state affects another; for example, a patient's death eliminates the possibility of subsequent readmissions. Going one step further from our previous works, ${ }^{12,21,25}$ we are interested in knowing whether HBEC is not just associated with the first readmission within 12 months, but also implies a lasting effect on increased readmission rates. The present study implicates two readmissions following the first release. The admission and the readmissions, together with the time out of hospital and death, were all modeled simultaneously as different states of the patients thanks to the multi-state statistical approach.

\section{Patients and methods Study design and data sources}

This is a noninterventional observational cohort study using linked real-world clinical and medical administrative data. The study cohort was extracted from the electronic medical records located at the Centre Hospitalier Universitaire de Sherbrooke (CHUS) and included all patients hospitalized for COPD for the first time at the CHUS between April 2006 and March 2013. Data were linked to the provincial administrative data acquired from the Régie de l'assurance maladie du Québec (RAMQ) and the Ministère de la Santé et des Services Sociaux to obtain all healthcare services used and outcomes. Additional data collected by manual extraction from medical charts consisted of smoking status; home oxygen use; baseline pulmonary function test (PFT) results up to 1 year following index hospitalization (PFT used, in order of priority: most recent PFT $<5$ years prior to admission, PFT $>1$ year after discharge, and PFT between 1998 and $>5$ years prior); baseline and discharge inhaler therapy; corticosteroid use within 48 hours before index admission, inpatient definitive treatment components, such as corticosteroids and/or antimicrobial agents; and date and time of the first corticosteroid dose. Using a unique encrypted identifier, patient files from different sources were linked to provide demographic characteristics, medical, and clinical information. This project was approved by the institutional ethics committee (Comité d'éthique de la recherche du CIUSSS de l'Estrie - CHUS \#2014-696, 13-181). AstraZeneca funded the study. However, the sponsor did not have any participation in the elaboration of the protocol, the data collection, the statistical analyses, nor the redaction of the manuscript.

\section{Study population}

\section{Inclusion and exclusion criteria}

The inclusion criteria were the following: all patients 40-84 years old having been hospitalized for COPD (main diagnosis ICD-10: J40-J44, COPD according to spirometry results, and current or former smokers with at least 10-pack-year) at the CHUS between April 2006 and March 2013, discharged alive, and without a previous hospitalization for asthma in the past 5 years. As done previously, the choice to include only patients treated with at least two respiratory drugs during hospitalization was made to increase the likelihood of a correct COPD diagnosis. ${ }^{27,28}$ Respiratory drugs were short acting beta agonist (SABA), long acting beta agonist (LABA), long acting muscarinic antagonists, 
inhaled corticosteroid (ICS), and theophylline. Further exclusion criteria were defined as follows: pneumonia, absence of obstructive pattern on PFT results, absence of a valid PFT result any time between 1998 and 1 year after the index hospitalization, COPD without exacerbation, and subjects mislabelled as COPD (never smokers with or without obstructive spirometry results and no mention of COPD in medical records). Patients purely labelled as asthmatics were also excluded, but we included patients with asthma-COPD overlap. In order to recruit only patients with a "first" COPD hospitalization, we excluded those that were hospitalized for COPD in the previous 5 years before the index hospitalization. To be able to accurately measure the blood eosinophil levels, we also excluded patients not "corticosteroid-free" at the time of blood sampling (defined as systemic corticosteroid use between 1 and 48 hours before the blood sampling).

\section{HBEC and normal blood eosinophil count (NBEC)}

The main stratifying variable in our study was binary (yes/no) and related to the blood eosinophil cell count $\geq 200$ cells $/ \mathrm{mL}$ and/or $\geq 2 \%$ of the total white blood cell (WBC) count on the first inpatient complete blood count available during the index hospitalization (including emergency department care). This threshold has previously shown high sensitivity for predicting sputum eosinophilia and was thus considered to indicate an "eosinophilic COPD patient". ${ }^{14}$

\section{Outcomes}

The patients have six possible Markov states ${ }^{29}$ in our study. Dates of admission and release are available from the hospital data allowing us to observe states and transitions. Patients in state 1 are admitted for the first time; patients in state 2 are released from the first hospitalization (out of first admission). State 3 indicates the first COPD-related readmission and patients in state 4 are released from their first COPD-related readmission (out of first readmission). State 5 indicates the second COPD-related readmission, and state 6 is death, which is the absorbing state. The date of death was obtained from hospital record of the patients and the RAMQ demographic database. For patients who were admitted and released on the same day, we count the length of stay as 0.5 day.

\section{Covariables}

Covariables that have been considered in statistical models are age, sex, intensity of used care index (NIRRU), Charlson comorbidity index (CCI), WBC index (maximum value), and a set of binary variables (yes/no) including intensive care unit stay, pneumonia, mental health diagnosis, WBC index $>10$, severe COPD (yes if saturated pulse $\mathrm{O}_{2}<90$ or arterial $\mathrm{pH}<7.35$, no otherwise), thorax scan, occupational therapist consultation, nutritionist consultation, physiotherapist consultation, social worker consultation, Bilevel Positive Airway Pressure (BiPAP), intubation and mechanical ventilation, oxygen, SABA, LABA, theophylline, ICS, long-acting anticholinergics, leukotriene receptor antagonists, oral corticosteroid (OCS), intravenous corticosteroid; antibiotic or antiviral, vaccine (flu or pneumonia), beta blocker, angiotensin converting enzyme inhibitor, statin, and benzodiazepine. These variables were selected because they may possibly influence the transitions of the states. The D'Hoore et al version of the $\mathrm{CCI}^{30}$ was calculated using diagnoses reported during a hospitalization or during a physician's visit in the year prior and including the index hospitalization. The NIRRU measures the relative amount of resources used during a hospitalization.

\section{Statistical analyses}

The study variables were compared between patients with HBEC and NBEC using the chi-squared test for categorical variables and the Wilcoxon rank test for continuous variables. Descriptive and summary analyses were performed at different time points to show the percentage of patients in each state, and comparisons were made between patients with HBEC and NBEC. Multi-state Markov model ${ }^{29}$ was applied to describe the process where the patients move through the six states in continuous time. The risk of moving from a state to another state was obtained from the matrix of transition intensities associated with the multi-state Markov model where the transition intensities are equivalent to hazard/ probability for a survival model $;{ }^{31}$ hence, we use the term transition probability to the next state from here onwards for ease of the readers. CIs of the transition probability are estimated with the delta method. Observed and expected frequencies were compared with Fisher's exact test. It should be avoided to have too many parameters in a Markov model when estimating the transition probabilities; ${ }^{32}$ in our case, three co-variables were included in the analysis each time to control for potential confounders. The three co-variables are age, sex, and a covariate that statistically distinguish $(P<0.1)$ HBEC patients from NBEC patients. All analyses were performed with the $\mathrm{R}$ package msm (version 3.4.3).

\section{Sensitivity analyses}

Sensitivity analyses on primary outcomes were performed with different definitions of HBEC, particularly $\geq 300$ cells $/ \mathrm{mL}$ or $\geq 3 \%$ of WBC. Sputum eosinophil 
$\geq 3 \%$ is considered as an accepted and standard threshold ${ }^{33,34}$ though there is still debate about the best eosinophil cutoff level and the choice may vary from one study to another.

To control for potential confounders, stepwise logistic regression predicting the first COPD-related readmission was implemented with backward selection starting from all variables in Table 1; three-suites of variables were chosen among the variables that remained after the backward selection. Random choices of three-suites of variables among all variables were also performed to check for robustness of the results; this included all three-suites, where age, sex, and another variable were put together; the reason is that some

Table I Patients' characteristics

\begin{tabular}{|c|c|c|c|c|c|c|c|}
\hline \multirow[t]{2}{*}{ Variables } & \multirow{2}{*}{$\begin{array}{l}\text { Total } \\
(n=479)\end{array}$} & \multicolumn{3}{|c|}{$\geq 300 \mathrm{cells} / \mathrm{mL}$ and $/ \mathrm{or} \geq 3 \%$} & \multicolumn{3}{|c|}{$\geq 200$ cells $/ \mathrm{mL}$ and $/$ or $\geq 2 \%$} \\
\hline & & $\begin{array}{l}\text { HBEC } \\
(n=103)\end{array}$ & $\begin{array}{l}\text { NBEC } \\
(n=376)\end{array}$ & $P$-value & $\begin{array}{l}\text { HBEC } \\
(n=I 73)\end{array}$ & $\begin{array}{l}\text { NBEC } \\
(n=306)\end{array}$ & $P$-value \\
\hline Age (years) & $68.9 \pm 9.4$ & $69.6 \pm 9.1$ & $68.8 \pm 9.5$ & 0.422 & $68.7 \pm 9.4$ & $69.1 \pm 9.4$ & 0.678 \\
\hline WBC & $12.7 \pm 5.4$ & $13 \pm 6.2$ & $12.6 \pm 5.2$ & 0.921 & $12.9 \pm 5.8$ & $12.6 \pm 5.2$ & 0.897 \\
\hline $\mathrm{CCl}$ & $0.9 \pm 1.4$ & $0.8 \pm 1.1$ & $0.9 \pm 1.5$ & 0.922 & $0.9 \pm 1.4$ & $0.8 \pm 1.4$ & 0.106 \\
\hline NIRRU & $1.0 \pm 0.8$ & $1.0 \pm 0.9$ & $1.0 \pm 0.8$ & 0.070 & $1.0 \pm 0.8$ & $1.0 \pm 0.8$ & 0.540 \\
\hline $\mathrm{FEV}_{1}$ & $51.2 \pm 16.8$ & $55.0 \pm 18.5$ & $50.1 \pm 16.2$ & 0.010 & $52.0 \pm 17.4$ & $50.7 \pm 16.5$ & 0.397 \\
\hline $\mathrm{FEV}_{1} / \mathrm{FVC}(\%)$ & $47.0 \pm 12.1$ & $48.1 \pm 13.7$ & $46.7 \pm 11.6$ & 0.352 & $47.0 \pm 12.9$ & $47.0 \pm 11.6$ & 0.964 \\
\hline Male & $249(52.0)$ & $61(59.2)$ & $188(50.0)$ & 0.097 & $98(56.6)$ & 151 (49.3) & 0.124 \\
\hline ICU & $38(7.9)$ & $8(7.8)$ & $30(8.0)$ & 0.944 & II (6.4) & $27(8.8)$ & 0.338 \\
\hline Pneumonia & $6(1.3)$ & $0(0)$ & $6(1.6)$ & 0.197 & $2(1.2)$ & $4(1.3)$ & 0.886 \\
\hline Mental health diagnosis & $255(53.2)$ & $55(53.4)$ & $200(53.2)$ & 0.970 & $94(54.3)$ & $161(52.6)$ & 0.717 \\
\hline$W B C>10$ & $304(63.5)$ & $63(6 \mid .2)$ & $24 I(64 . I)$ & 0.584 & $105(60.7)$ & $199(65.0)$ & 0.343 \\
\hline Severe COPD & $239(49.9)$ & 44 (42.7) & $195(51.9)$ & 0.100 & $82(47.4)$ & I 57 (5I.3) & 0.411 \\
\hline $\mathrm{CT}$ thorax scan & $54($ II.3) & $15(14.6)$ & $39(10.4)$ & 0.233 & $24(13.9)$ & $30(9.8)$ & 0.176 \\
\hline Occupational therapist & $5(1.0)$ & $I(I .0)$ & $4(1.1)$ & 0.934 & $2(1.2)$ & $3(1.0)$ & 0.856 \\
\hline Nutritionist & $16(3.3)$ & $\mathrm{I}(\mathrm{I} .0)$ & $15(4.0)$ & 0.131 & $4(2.3)$ & $12(3.9)$ & 0.346 \\
\hline Physiotherapist & $35(7.3)$ & $4(3.9)$ & $31(8.2)$ & 0.132 & $12(6.9)$ & $23(7.5)$ & 0.815 \\
\hline Social worker & $28(5.8)$ & $6(5.8)$ & $22(5.9)$ & 0.992 & II (6.4) & $17(5.6)$ & 0.719 \\
\hline BiPAP & $55(11.5)$ & $6(5.8)$ & $49(13.0)$ & 0.042 & $12(6.9)$ & $43(14.1)$ & 0.019 \\
\hline Intubation and mechanical ventilation & $69(14.4)$ & $9(8.7)$ & $60(16.0)$ & 0.064 & $17(9.8)$ & $52(17.0)$ & 0.032 \\
\hline GOLD stage (by $\mathrm{FEV}_{1}$ ) & & & & 0.136 & & & 0.726 \\
\hline I & $30(6.3)$ & $\mathrm{II}(\mathrm{I} 0.7)$ & $19(5.0)$ & & $13(7.5)$ & $17(5.6)$ & \\
\hline II & $216(45.1)$ & $49(47.6)$ & $167(44.4)$ & & $80(46.2)$ & $136(44.4)$ & \\
\hline III & $196(40.9)$ & $36(35.0)$ & $160(42.6)$ & & $66(38.2)$ & $130(42.5)$ & \\
\hline IV & $37(7.7)$ & $7(6.8)$ & $30(8.0)$ & & $14(8.1)$ & $23(7.5)$ & \\
\hline Oxygen during hospitalization & $44 I(92.1)$ & $95(92.2)$ & $346(92.0)$ & 0.944 & $158(91.3)$ & $283(92.5)$ & 0.653 \\
\hline SABA & $478(99.8)$ & $103(100)$ & $375(99.7)$ & 0.600 & $172(99.4)$ & $306(100)$ & 0.183 \\
\hline LABA & $295(61.6)$ & $61(59.2)$ & $234(62.2)$ & 0.578 & $109(63.0)$ & $186(60.8)$ & 0.631 \\
\hline Theophylline & $13(2.7)$ & $3(2.9)$ & $10(2.7)$ & 0.889 & $4(2.3)$ & $9(2.9)$ & 0.684 \\
\hline ICS & $302(63.0)$ & $64(62.1)$ & $238(63.3)$ & 0.829 & 114 (65.9) & $188(6 \mid .4)$ & 0.332 \\
\hline LAAC & 47I (98.3) & $99(96.1)$ & $372(98.9)$ & 0.048 & $169(97.7)$ & $302(98.7)$ & 0.410 \\
\hline LTRA & $6(1.3)$ & $I(I .0)$ & $5(1.3)$ & 0.772 & $2(1.2)$ & $4(1.3)$ & 0.886 \\
\hline OCS & $172(35.9)$ & $34(33.0)$ & 138 (36.7) & 0.489 & $62(35.8)$ & $110(35.9)$ & 0.981 \\
\hline IVCS & $118(24.6)$ & $25(24.3)$ & $93(24.7)$ & 0.923 & $43(24.9)$ & $75(24.5)$ & 0.933 \\
\hline Antibiotic & 367 (76.6) & $62(60.2)$ & $305(81.1)$ & $<\mathbf{0 . 0 0 1}$ & 118 (68.2) & $249(81.4)$ & 0.001 \\
\hline Vaccine & $21(4.4)$ & $6(5.8)$ & $15(4.0)$ & 0.420 & $9(5.2)$ & $12(3.9)$ & 0.511 \\
\hline $\mathrm{BB}$ & $92(19.2)$ & $13(12.6)$ & $79(21.0)$ & 0.055 & $28(16.2)$ & 64 (20.9) & 0.207 \\
\hline ACEI & $212(44.3)$ & 46 (44.7) & $166(44.1)$ & 0.926 & $77(44.5)$ & $135(44.1)$ & 0.934 \\
\hline Statin & 238 (49.7) & 49 (47.6) & $189(50.3)$ & 0.628 & $87(50.3)$ & 151 (49.3) & 0.843 \\
\hline Benzodiazepine & $122(25.5)$ & $30(29.1)$ & $92(24.5)$ & 0.336 & $45(26.0)$ & 77 (25.2) & 0.838 \\
\hline
\end{tabular}

Notes: $\mathrm{N}(\%)$ or mean \pm SD. Chi-squared test for categorical variables and Wilcoxon rank test for continuous variables. Bold values indicate a statistical significant difference between groups. Variable names: NIRRU, CCI, WBC, ICU stay, FEV (postbroncho, \% predicted), occupational therapist consultation, nutritionist consultation, physiotherapist consultation, social worker consultation, BiPAP, intubation and mechanical ventilation, oxygen during hospitalization, SABA, LABA, ICS, LAAC, LTRA, OCS, IVCS, Vaccine (flu or pneumonia), ACEl, severe COPD (yes if saturated pulse $\mathrm{O}_{2}<90$ or arterial $\mathrm{pH}<7.35$, no otherwise).

Abbreviations: ACEl, angiotensin converting enzyme inhibitor; $\mathrm{BB}$, beta blocker; BiPAP, Bilevel Positive Airway Pressure; $\mathrm{CCl}$, Charlson comorbidity index; $\mathrm{CT}$, computed tomography; HBEC, high blood eosinophil count; ICS, inhaled corticosteroid; ICU, intensive care unit; IVCS, intravenous corticosteroid; LAAC, long-acting anticholinergics; LABA, long acting beta agonist; LTRA, leukotriene receptor antagonists; NBEC, normal blood eosinophil count; NIRRU, intensity of used care index; OCS, oral corticosteroid; SABA, short acting beta agonist; WBC, white blood cell. 
variables such as prednisolone dose (OCS) might affect both readmissions and death even if no significant difference was observed in the baseline table.

\section{Results}

Overall, 1,440 patients satisfied our criteria. For 1,129 (78.4\%) of them, this was their first COPD hospitalization over a 5-year period. Among this cohort of "first" COPDhospitalization, 479 (42.4\%) patients were retained after applying exclusion criteria (Figure 1).

Among the 479 patients, 173 have HBEC using the main definition ( $\geq 200$ cells $/ \mathrm{mL}$ and/or $\geq 2 \%$ of the total WBC count). For sensitivity analysis, 103 patients were considered having HBEC using definitions of $\geq 300$ cells $/ \mathrm{mL}$ and/or $\geq 3 \%$ of the total WBC count. Characteristics between HBEC and NBEC patients were compared in Table 1. The characteristics are generally similar between HBEC patients and NBEC patients except for a few variables, notably those related to resource use (eg, NIRRU). Antibioviral (antibiotic or antiviral use) is the variable that distinguishes the most between HBEC and NBEC patients with both definitions $(P<0.001)$.
The descriptive results in Figure 2 compare the observed percentages of patients in different states. Each column in Figure 2 is a snapshot of the percentages at an exact moment in time and the comparison was made at an interval of a month. At day 0 , all patients were in state 1 , namely the first hospitalization. After 30 days, for instance, certain patients had already started with the second hospitalization (first readmission); some of the patients were in hospital (light blue color) and some had been released from their second hospitalization after 30 days (pink color). In this way, it is clear from Figure 2 that the HBEC patients had faster readmissions (whether or not they had been released from the hospitalization at the moment of the snapshot). The percentage of death, in contrast, was lower among the HBEC patients in general. Even if the percentage of $\mathrm{HBEC}$ patients who died was very slightly higher at the end of 5, 6 and 7 months, the difference became obvious with time and the tendency was rather clear at the end of a year (Figure 2A and $\mathrm{B}$ ). The difference between the two groups is relatively less visible in Figure 2A because of the relatively low cutoff ( $\geq 200$ cells/ $\mu \mathrm{L}$ and/or $\geq 2 \%$ ); it becomes clearer with a

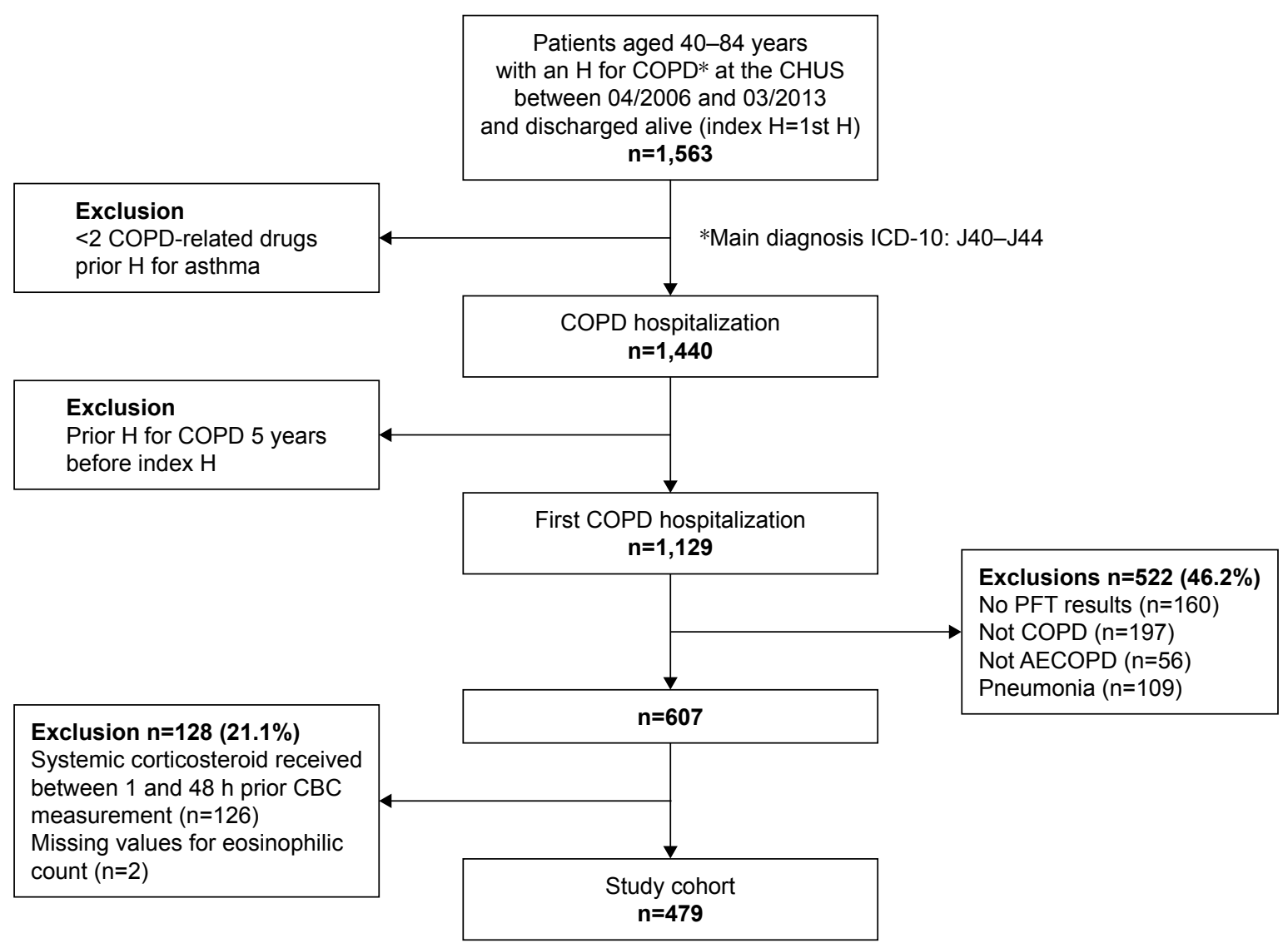

Figure I Flowchart of patient enrollment process.

Abbreviations: AECOPD, acute exacerbations of COPD; CBC, complete blood counts; CHUS, Centre Hospitalier Universitaire de Sherbrooke; PFT, pulmonary function test. 

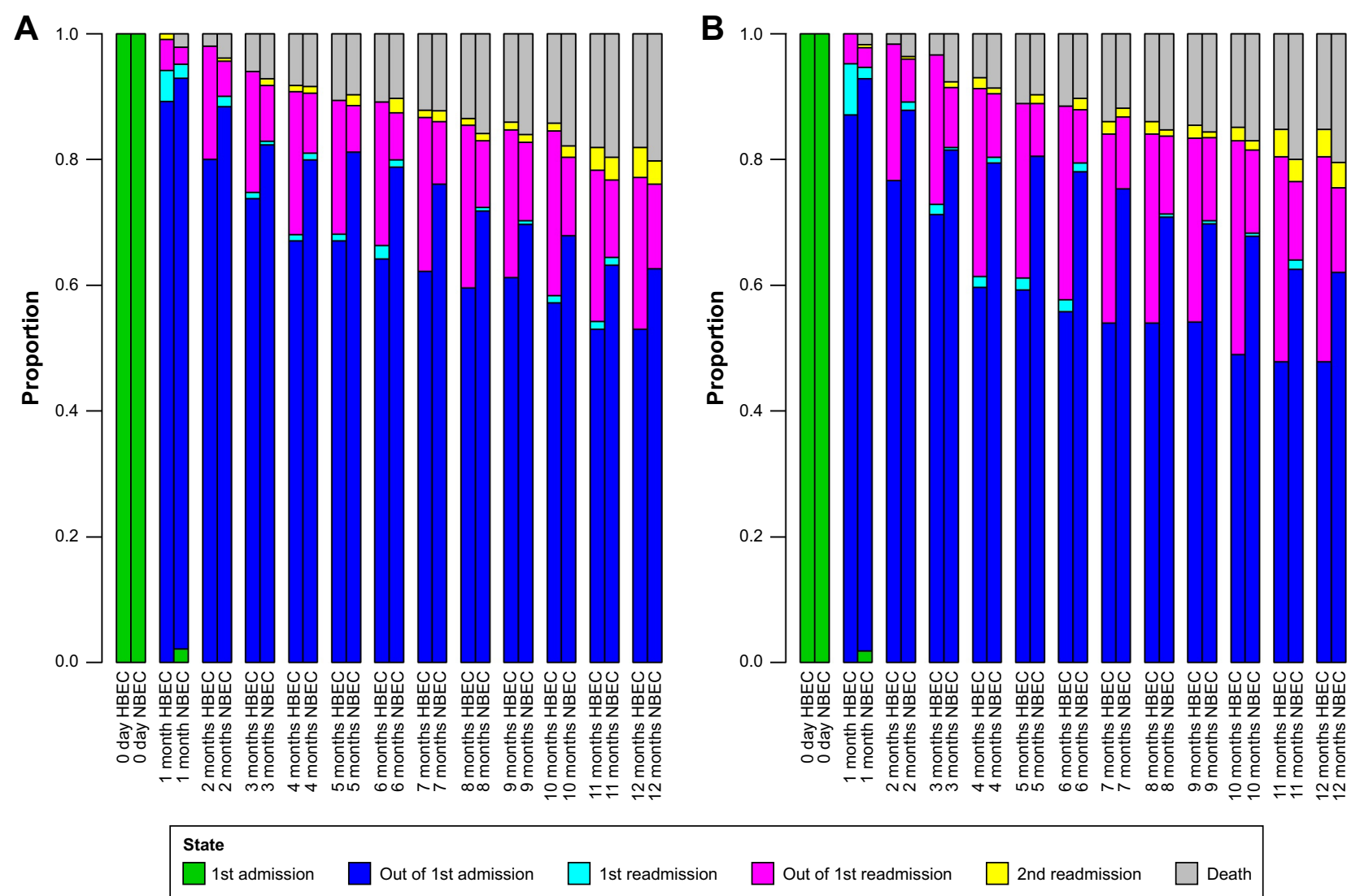

Figure 2 Observed snapshot percentages of patients in the six states, from day 0 to 12 months with an interval of 30 days. Snapshots are taken at each exact point in time. Notes: (A) HBEC patients (defined as $\geq 200$ cells $/ \mu \mathrm{L}$ and/or $\geq 2 \%$ of the WBC count) are compared to NBEC patients. (B) HBEC patients (defined as $\geq 300$ cells/ $\mu \mathrm{L}$ and/or $\geq 3 \%$ of the WBC count) are compared to NBEC patients.

Abbreviations: HBEC, high blood eosinophil count; NBEC, normal blood eosinophil count; WBC, white blood cell.

higher cutoff ( $\geq 300$ cells $/ \mu \mathrm{L}$ and/or $\geq 3 \%$ ) in Figure $2 \mathrm{~B}$. In Figure $\mathrm{S} 1$, we further increased the cutoff to $\geq 400$ cells $/ \mu \mathrm{L}$ and/or $\geq 4 \%$ where the results are more evident.

Figure 3 reports the transition probability to the next state where the arrows show the directions of the transitions. The results were obtained controlling for age, sex, and antibioviral (antibiotic or antiviral use). With the main definition of $\operatorname{HBEC}$ ( $\geq 200$ cells $/ \mathrm{mL}$ and/or $\geq 2 \%$ of the total WBC count) the probability to transit to a first readmission is $0.74(95 \%$ CI, 0.66-0.83) for HBEC patients in comparison with 0.70 ( $95 \%$ CI, 0.63-0.77) for NBEC patients, a difference of about $4 \%$. Once the patients are readmitted to hospital (state 3, first readmission), the probability to be released alive is 0.97 (95\% CI, 0.93-1.00) for HBEC patients in comparison with 0.95 ( $95 \%$ CI, 0.91-0.99) for NBEC patients. The probability to have a second readmission is $0.91(95 \% \mathrm{CI}, 0.84-1.00)$ for HBEC patients, $8 \%$ higher than 0.83 ( $95 \%$ CI, 0.74-0.92) for NBEC patients. Concerning death, the transition probability from state 2 is 0.26 (95\% CI, 0.18-0.36) for HBEC patients and $0.30(95 \% \mathrm{CI}, 0.24-0.38)$ for NBEC patients; the transition probability from state 3 to death is $0.03(95 \% \mathrm{CI}$,
0.01-0.11) for HBEC patients and 0.05 (95\% CI, 0.02-0.12) for NBEC patients; the transition probability from state 4 to death is 0.09 (95\% CI, 0.04-0.21) for HBEC patients and 0.17 (95\% CI, 0.10-0.30) for NBEC patients (Figure 3A).

For sensitivity analyses ( $\geq 300$ cells/mL and/or $\geq 3 \%$ of the total WBC count), the probability to transit to a first readmission is $0.81(95 \% \mathrm{CI}, 0.72-0.92)$ for HBEC patients in comparison with 0.69 (95\% CI, 0.62-0.75) for NBEC patients, a difference of about $12 \%$ (Figure 3B). Once the patients are readmitted to hospital (state 3, first readmission), the probability to be released alive is 0.98 (95\% CI, 0.95-1.00) for HBEC patients in comparison with 0.95 (95\% CI, 0.91-0.99) for NBEC patients. The probability to have a second readmission is $0.96(95 \% \mathrm{CI}, 0.90-1.00)$ for HBEC patients, $14 \%$ higher than 0.82 (95\% CI, 0.74-0.91) for NBEC patients. Concerning death, the transition probability from state 2 is 0.19 (95\% CI, 0.11-0.31) for HBEC patients and 0.31 (95\% CI, 0.26-0.38) for NBEC patients; the transition probability from state 3 to death is $0.02(95 \% \mathrm{CI}$, $0.00-0.12)$ for HBEC patients and 0.05 (95\% CI, 0.02-0.11) for NBEC patients; the transition probability from state 4 to 


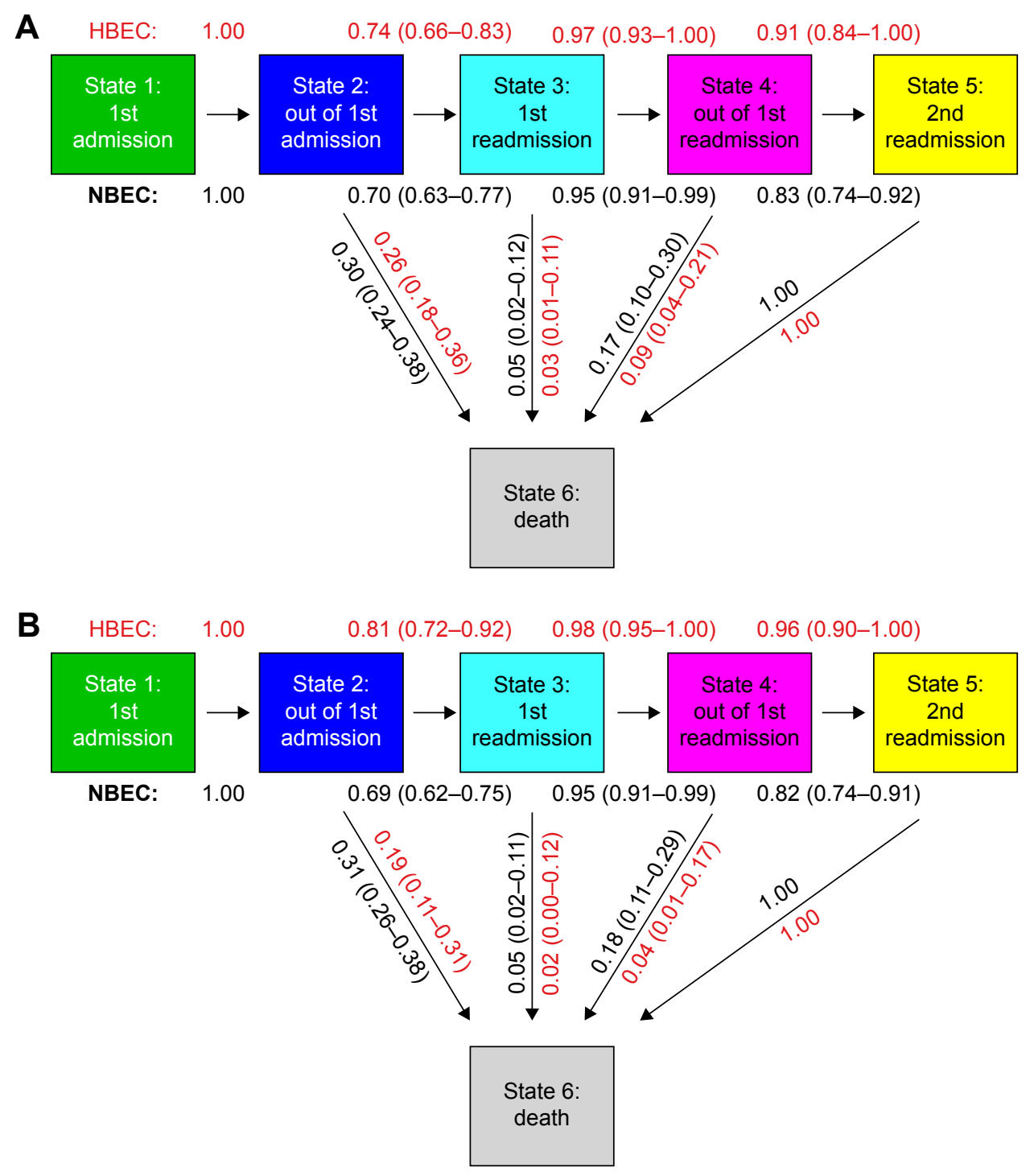

Figure 3 (A) Transition probability to the next states with $95 \% \mathrm{Cls}$ for HBEC patients (defined as $\geq 200$ cells/ $\mu \mathrm{L}$ and/or $\geq 2 \%$ of the WBC count) and NBEC patients. (B) Transition probability to the next states with $95 \% \mathrm{Cls}$ for $\mathrm{HBEC}$ patients (defined as $\geq 300$ cells/ $\mu \mathrm{L}$ and/or $\geq 3 \%$ of the WBC count) and NBEC patients. The transition probability from state I to state 2 is equal to 1.00 because we excluded patients who died during the first hospitalization. The transition probability from state 5 to state 6 is 1.00 because state 5 is the final state of alive patients in our model.

Abbreviations: HBEC, high blood eosinophil count; NBEC, normal blood eosinophil count; WBC, white blood cell.

death is $0.04(95 \% \mathrm{CI}, 0.01-0.17)$ for HBEC patients and 0.18 (95\% CI, 0.11-0.29) for NBEC patients.

\section{Discussion}

The main finding of the present study was that greater blood eosinophil cell counts at admission for the first severe COPD exacerbation was associated with higher probability of readmissions and lower probability of death within a year following the initial first admission. In case either death or a future readmission is the next state, HBEC patients (defined as $\geq 200$ cells $/ \mu \mathrm{L}$ and/or $\geq 2 \%$ of the WBC count) were $4 \%$ more likely to have a readmission (instead of death) after being released from the first hospitalization. For patients who were released alive from their first readmission, the HBEC patients were $8 \%$ more likely to have a second readmission (instead of death) as their next state. The difference enlarged with the cutoff for the definition of HBEC showing consistency of our results associated with the influence of eosinophil cell counts on readmissions throughout our sensitivity analyses; HBEC patients (defined as $\geq 300$ cells $/ \mu \mathrm{L}$ and/or $\geq 3 \%$ of the WBC count) were $12 \%$ more likely to have a readmission (instead of death) after being released from the first hospitalization. For patients who were released alive from their first readmission, the HBEC patients were $14 \%$ more likely to have a second readmission (instead of death) as their next state. 
Our previous studies ${ }^{12,21,25}$ have demonstrated association between HBEC and the first COPD-related hospital readmission within a year. Extending our analyses to include two readmissions and death simultaneously, this study followed the method of Couillard et $\mathrm{a}^{21}$ and only included the patients with no corticosteroid treatment $\leq 48$ hours. Additionally, it is well known that ICS may reduce the risk of exacerbation; ${ }^{16-18}$ the proportion of patients who used ICS after being discharged did not differ between the two groups in this study, hence, it is unlikely that the results would have been distorted by potential impact associated with ICS.

Exacerbation events are typically treated as independent phenomena in practice, ${ }^{35}$ it has been argued nonetheless that a more rapid administration of the appropriate therapy could be enabled by available clinical information from previous exacerbations. ${ }^{36}$ Going a step further from our previous findings, ${ }^{12,21,25}$ we are interested here in the trajectories of patients as a whole picture after their release from a "first" hospitalization. To our knowledge, very few studies have explored within-subject state transitions specifically for COPD patients, though similar approaches have been applied elsewhere. ${ }^{37} \mathrm{~A}$ recent work described, for the first time as claimed by the authors, the within-subject stability of the lung microbiome in COPD and the nonrandom nature of exacerbations over time by modeling exacerbation phenotypes as a Markov Chain; they found significantly nonrandom transition for eosinophilic exacerbations (and for bacterial exacerbations but not for viral exacerbations). ${ }^{8}$

Intuitively, one might imagine that patients who are more likely to be readmitted are also at higher risk of death; yet we, as others, find more readmissions and fewer deaths for HBEC patients, and this may be associated with shorter length of stay and better in-hospital outcomes. For example, invasive mechanical ventilation rates were significantly lower $(9.8 \%$ vs $17.0 \% P=0.032$ ) for HBEC. Likewise, previous studies have found a shorter length of stay ${ }^{19}$ and higher short-term treatment success for eosinophilic patients, who had nonetheless more risks of relapse. ${ }^{23,38}$ which is concordant with our results. Concerning death, it has been documented that eosinopenia was associated with higher in-hospital mortality in acute exacerbations of COPD, ${ }^{39,40}$ Which is also in line with our findings here while our focus is rather on eosinophilia. Most probably, though associated with increased readmissions/relapses, eosinophilia represents a marker of less severe noninfectious exacerbations ${ }^{14}$ as well as a "treatable trait". ${ }^{20,41,42}$

The results of this study may suggest two distinct populations affected by COPD exacerbation, involving specific pathophysiological process and resulting in different disease trajectories. Higher differences were observed with a 300 cell and/or 3\% cutoff in our sensitivity analyses. This is in line with the current state of the scientific literature. First, our finding is concordant with our previous analyses regarding adverse clinical outcomes in eosinophilic COPD. The fact that higher eosinophil cell counts lead to more readmissions ${ }^{12,21}$ and higher costs ${ }^{25}$ mirrors our current finding that this may also be associated with higher subsequent readmissions. Second, we recognize that the current trend of thinking in the domain of eosinophil inflammation in COPD is that no precise cutoff confers a sudden stepwise increase in risk. More likely, there exists a non-linear correlation between eosinophil cell counts and increased adverse outcomes, as observed recently by Bafadhel et $\mathrm{al}^{20}$ and discussed thoroughly by Pascoe et al ${ }^{43}$ Though we had initially chosen a $200 / 2 \%$ cutoff in our protocol, we believe that the use of a higher cutoff might have provided stronger differences, although this may also have decreased the size of our HBEC group.

The major strength of the present study is its longitudinal aspect of within-patient trajectory accounting for the exact time between state transitions. The pathophysiologic-driven design, the combination of hospital and administrative data, the consideration of relative timing of systemic corticosteroid administration, and the different definitions of eosinophilia, as well as the confirmation of COPD diagnosis with spirometry and smoking history, all contributed to objectiveness of the results. Though we cannot guarantee that patients did not suffer from comorbid lung conditions, such as bronchiectasis or a minor beginning of interstitial lung disease, we are confident that our careful manual review of clinical and spirometric data led to inclusion of patients whose main clinical and physiological picture was that of COPD. Even if we cannot examine all potential variables that may influence the outcomes, we tried our best to include the most important ones. Nevertheless, our study must be considered in light of several limitations. First of all, the study sample size is small which is a limitation regarding the interpretation and generalization of the results; the study was conducted in a local hospital, limiting potentially the geographical scope of the findings; while the geographical limitation might reduce further confounding, the particular population reduced possibilities to explore more detailed relations with different maintenance COPD medications that were observed in other studies. ${ }^{44,45}$ The usual methods of identification are either during the exacerbation itself or during a steady state blood test. It is not ideal to consider that eosinophilia during exacerbation can be extrapolated to subsequent ones because the inflammation can sometimes be specific to the pathologic 
process underlying the index exacerbation. This limitation is due to availability of information; meanwhile, the partition of patients into two distinct groups facilitates longitudinal analysis. Additionally, the difference between HEBC patients and NEBC patients was not as remarkable as observed by Couillard et $\mathrm{al}^{21}$ when HEBC was defined as $\geq 200$ cells $/ \mathrm{mL}$ and/or $\geq 2 \%$ of the total WBC count. This could be resulted from the different statistical approach; our sample size was also larger, where we had selected milder COPD patients who were less prone to readmissions.

\section{Conclusion}

After being released from the first COPD hospitalization, HEBC patients have higher risk of COPD-related readmission within a year. For patients released alive from the first COPD-related readmission, HEBC patients also have more risk to be readmitted for the second time. Meanwhile, the risk of death is lower for HEBC patients.

\section{Acknowledgments}

This study was conducted with funding support from AstraZeneca Canada Inc. The sponsor had no role in the design of the study, the collection and analysis of the data, or the preparation of the manuscript. Dr Li thanks Xinjiang University for the funding (116/62008056). Drs Vanasse, Poder, and Larivée are members of the Fonds de Recherche Québec Santé (FRQS)-funded Centre de recherche du CHUS.

\section{Disclosure}

AV and TGP report grants from AstraZeneca Canada Inc., during the conduct of the study; PL reports grants and personal fees from AstraZeneca, Boehringer Ingelheim, and Novartis, grants from Sanofi, and personal fees from Merck, outside the submitted work. The other authors report no conflicts of interest in this work.

\section{References}

1. Vestbo J, Hurd SS, Agustí AG, et al. Global strategy for the diagnosis, management, and prevention of chronic obstructive pulmonary disease: GOLD executive summary. Am J Respir Crit Care Med. 2013; 187(4):347-365.

2. Cruz AA. Global Surveillance, Prevention and Control of Chronic Respiratory Diseases: A Comprehensive Approach. Switzerland: World Health Organization; 2007.

3. Information (CIHI) CI for H. All-Cause Readmission to Acute Care and Return to the Emergency Department. Ottawa: CIHI; 2012.

4. Dorsey K, Grady J, Desair N; Centers Medicare Medicaid Services; 2015. 2015 Condition-Specific Measures Updates and Specifications Report Hospital-Level 30-Day Risk-Standardized Readmission Measures. Available from: https://www.qualitynet.org/dcs/BlobServer?blobkey=id\&blobn ocache $=$ true $\&$ blobwhere $=1228890435217 \&$ blobheader $=$ multipart $\% 2$ Foct etstream\&blobheadername $1=$ Content-Disposition\&blobheadervalue $1=$ att achment\%3Bfilename\%3DRdmn_AMIHFPNCOPDSTK_Msr_UpdtRpt. pdf\&blobcol=urldata\&blobtable=MungoBlobs. Accessed January 7, 2019.
5. Spivack SB, Bernheim SM, Forman HP, Drye EE, Krumholz HM Hospital cardiovascular outcome measures in federal pay-for-reporting and pay-for-performance programs: a brief overview of current efforts. Circ Cardiovasc Qual Outcomes. 2014;7(5):627-633.

6. Poder TG, Kouakou CRC, Bouchard PA, et al. Cost-effectiveness of $\mathrm{FreeO}_{2}$ in patients with chronic obstructive pulmonary disease hospitalised for acute exacerbations: analysis of a pilot study in Quebec. BMJ Open. 2018;8(1):e018835.

7. Vanasse A, Courteau J, Couillard S, Beauchesne M-F, Larivée P. Predicting one-year mortality after a "first" hospitalization for chronic obstructive pulmonary disease: an eight-variable assessment score tool. COPD. 2017;14(5):490-497.

8. Mayhew D, Devos N, Lambert C, et al. Longitudinal profiling of the lung microbiome in the AERIS study demonstrates repeatability of bacterial and eosinophilic COPD exacerbations. Thorax. 2018;73(5):422-430.

9. Roca J, Vargas C, Cano I, et al. Chronic obstructive pulmonary disease heterogeneity: challenges for health risk assessment, stratification and management. J Transl Med. 2014;12(Suppl 2):S3.

10. Agusti A, Calverley PM, Celli B, et al. Characterisation of COPD heterogeneity in the ECLIPSE cohort. Respir Res. 2010;11(1):122.

11. Sethi S, Murphy TF. Infection in the pathogenesis and course of chronic obstructive pulmonary disease. N Engl J Med. 2008;359(22):2355-2365.

12. Bélanger M, Couillard S, Courteau J, et al. Eosinophil counts in first COPD hospitalizations: a comparison of health service utilization. Int J Chron Obstruct Pulmon Dis. 2018;13:3045-3054.

13. Bafadhel M, Pavord ID, Russell REK. Eosinophils in COPD: just another biomarker? Lancet Respir Med. 2017;5(9):747-759.

14. Bafadhel M, Mckenna S, Terry S, et al. Acute exacerbations of chronic obstructive pulmonary disease: identification of biologic clusters and their biomarkers. Am J Respir Crit Care Med. 2011;184(6): 662-671.

15. Bafadhel M, Davies L, Calverley PM, Aaron SD, Brightling CE, Pavord ID. Blood eosinophil guided prednisolone therapy for exacerbations of COPD: a further analysis. Eur Respir J. 2014;44(3):789-791.

16. Pascoe S, Locantore N, Dransfield MT, Barnes NC, Pavord ID. Blood eosinophil counts, exacerbations, and response to the addition of inhaled fluticasone furoate to vilanterol in patients with chronic obstructive pulmonary disease: a secondary analysis of data from two parallel randomised controlled trials. Lancet Respir Med. 2015;3(6):435-442.

17. Siddiqui SH, Guasconi A, Vestbo J, et al. Blood eosinophils: a biomarker of response to extrafine beclomethasone/formoterol in chronic obstructive pulmonary disease. Am J Respir Crit Care Med. 2015; 192(4):523-525.

18. Pavord ID, Lettis S, Locantore N, et al. Blood eosinophils and inhaled corticosteroid/long-acting $\beta-2$ agonist efficacy in COPD. Thorax. 2016;71(2):118-125.

19. Bafadhel M, Greening NJ, Harvey-Dunstan TC, et al. Blood eosinophils and outcomes in severe hospitalized exacerbations of COPD. Chest. 2016;150(2):320-328.

20. Bafadhel M, Peterson S, de Blas MA, et al. Predictors of exacerbation risk and response to budesonide in patients with chronic obstructive pulmonary disease: a post-hoc analysis of three randomised trials. Lancet Respir Med. 2018;6(2):117-126.

21. Couillard S, Larivée P, Courteau J, Vanasse A. Eosinophils in COPD exacerbations are associated with increased readmissions. Chest. 2017; 151(2):366-373.

22. Vedel-Krogh S, Nielsen SF, Lange P, Vestbo J, Nordestgaard BG. Blood eosinophils and exacerbations in chronic obstructive pulmonary disease. The Copenhagen General Population Study. Am J Respir Crit Care Med. 2016;193(9):965-974.

23. Prins HJ, Duijkers R, Lutter R, et al. Blood eosinophilia as a marker of early and late treatment failure in severe acute exacerbations of COPD. Respir Med. 2017;131:118-124.

24. Duman D, Aksoy E, Agca MC. Erratum: The utility of inflammatory markers to predict readmissions and mortality in COPD cases with or without eosinophilia [corrigendum]. Int J Chron Obstruct Pulmon Dis. 2016;11:417. 
25. Poder TG, Carrier N, Bélanger M, et al. Eosinophil counts in first COPD hospitalizations: a 1-year cost analysis in Quebec, Canada. Int J Chron Obstruct Pulmon Dis. 2018;13:3065-3076.

26. Chung LP, Winship P, Phung S, Lake F, Waterer G. Five-year outcome in COPD patients after their first episode of acute exacerbation treated with non-invasive ventilation. Respirology. 2010;15(7):1084-1091.

27. Suissa S, Dell'Aniello S, Ernst P. Long-term natural history of chronic obstructive pulmonary disease: severe exacerbations and mortality. Thorax. 2012;67(11):957-963.

28. Ho TW, Tsai YJ, Ruan SY, et al. In-hospital and one-year mortality and their predictors in patients hospitalized for first-ever chronic obstructive pulmonary disease exacerbations: a nationwide population-based study. PLoS One. 2014;9(12):e114866.

29. Cox DR, HD Miller. The Theory of Stochastic Processes. London: Methuen Co Ltd; 1965.

30. D'Hoore W, Bouckaert A, Tilquin C. Practical considerations on the use of the Charlson comorbidity index with administrative data bases. $J$ Clin Epidemiol. 1996;49(12):1429-1433.

31. Jackson CH. flexsurv: A Platform for Parametric Survival Modeling in R. J Stat Softw. 2016;70(8):1-33.

32. Jackson CH. Multi-state models for panel data: the msm package for R. J Stat Softw. 2011;38(8):28.

33. Green RH, Brightling CE, Woltmann G, Parker D, Wardlaw AJ, Pavord ID. Analysis of induced sputum in adults with asthma: identification of subgroup with isolated sputum neutrophilia and poor response to inhaled corticosteroids. Thorax. 2002;57(10):875-879.

34. Castro M, Zangrilli J, Wechsler ME, et al. Reslizumab for inadequately controlled asthma with elevated blood eosinophil counts: results from two multicentre, parallel, double-blind, randomised, placebo-controlled, phase 3 trials. Lancet Respir Med. 2015;3(5):355-366.

35. Hillas G, Perlikos F, Tzanakis N. Acute exacerbation of COPD: is it the "stroke of the lungs"? Int J Chron Obstruct Pulmon Dis. 2016;11:1579.
36. Woodruff PG, Agusti A, Roche N, Singh D, Martinez FJ. Current concepts in targeting chronic obstructive pulmonary disease pharmacotherapy: making progress towards personalised management. Lancet. 2015;385(9979):1789-1798.

37. Nathoo FS, Dean CB. Spatial multistate transitional models for longitudinal event data. Biometrics. 2008;64(1):271-279.

38. Saltürk C, Karakurt Z, Adiguzel N, et al. Does eosinophilic COPD exacerbation have a better patient outcome than non-eosinophilic in the intensive care unit? Int J Chron Obstruct Pulmon Dis. 2015; 10:1837.

39. Holland M, Alkhalil M, Chandromouli S, Janjua A, Babores M. Eosinopenia as a marker of mortality and length of stay in patients admitted with exacerbations of chronic obstructive pulmonary disease. Respirology. 2010;15(1):165-167.

40. Steer J, Gibson J, Bourke SC. The DECAF Score: predicting hospital mortality in exacerbations of chronic obstructive pulmonary disease. Thorax. 2012;67(11):970-976.

41. Agusti A, Bel E, Thomas M, et al. Treatable traits: toward precision medicine of chronic airway diseases. Eur Respir J. 2016;47(2): 410-419.

42. Barnes NC, Sharma R, Lettis S, Calverley PM. Blood eosinophils as a marker of response to inhaled corticosteroids in COPD. Eur Respir J. 2016;47(5):1374-1382.

43. Pascoe S, Pavord I, Hinds D, Locantore N, Barnes N. The association between blood eosinophils and risk and treatment outcome in COPD is not dichotomised. Lancet Respir Med. 2018;6(5):e18.

44. Huang YJ, Sethi S, Murphy T, Nariya S, Boushey HA, Lynch SV. Airway microbiome dynamics in exacerbations of chronic obstructive pulmonary disease. J Clin Microbiol. 2014;52(8):2813-2823.

45. Millares L, Ferrari R, Gallego M, et al. Bronchial microbiome of severe COPD patients colonised by Pseudomonas aeruginosa. Eur J Clin Microbiol Infect Dis. 2014;33(7):1101-1111. 


\section{Supplementary material}

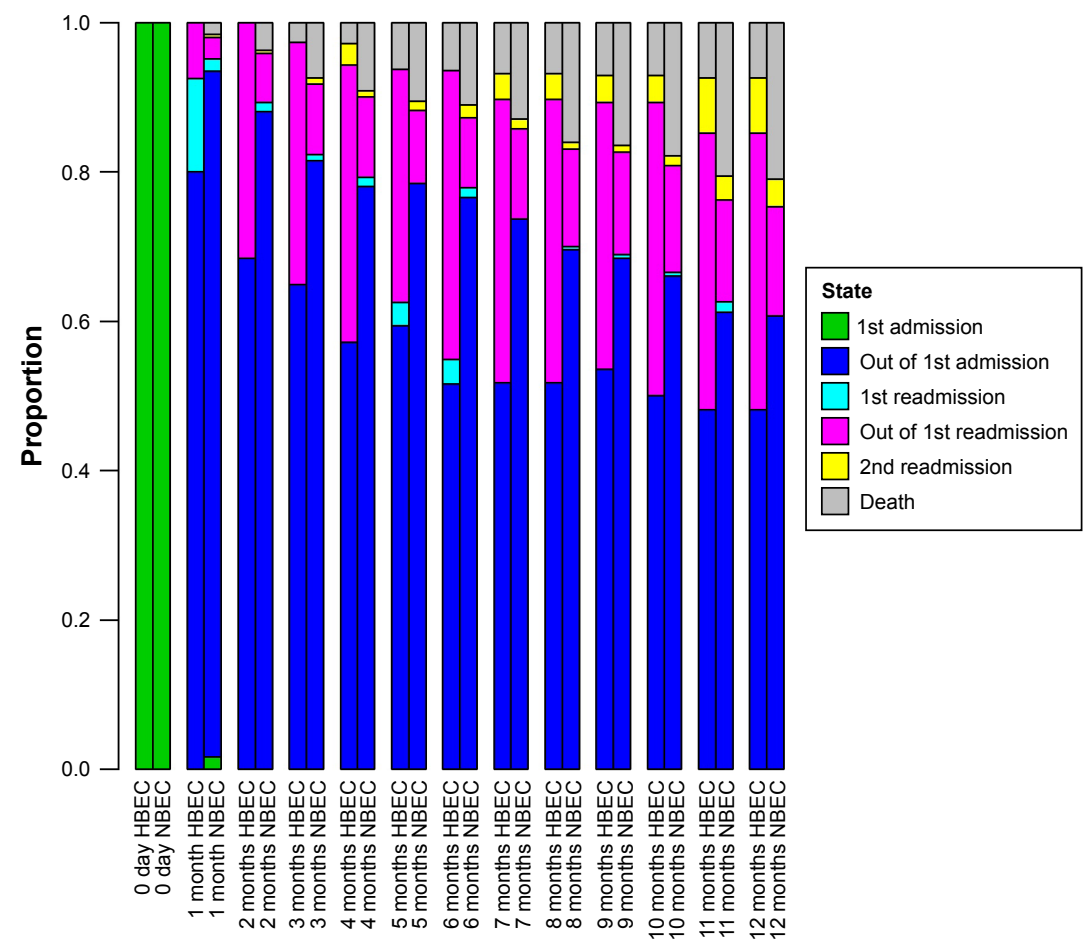

Figure SI Observed snapshot percentages of patients in the six states, from day 0 to 12 months with an interval of 30 days. Snapshots are taken at each exact point in time. HBEC patients (defined as $\geq 400$ cells $/ \mu \mathrm{L}$ and/or $\geq 4 \%$ of the WBC count) are compared to NBEC patients.

Abbreviations: HBEC, high blood eosinophil count; NBEC, normal blood eosinophil count; WBC, white blood cell.

\section{Publish your work in this journal}

The International Journal of COPD is an international, peer-reviewed journal of therapeutics and pharmacology focusing on concise rapid reporting of clinical studies and reviews in COPD. Special focus is given to the pathophysiological processes underlying the disease, intervention programs, patient focused education, and self management protocols
This journal is indexed on PubMed Central, MedLine and CAS. The manuscript management system is completely online and includes a very quick and fair peer-review system, which is all easy to use. Visit http://www.dovepress.com/testimonials.php to read real quotes from published authors. 